\title{
Reflections on the 2018 Nobel Memorial Prize Awarded to Paul Romer
}

\author{
BEATRICE CHERRIER \\ CNRS \& THEMA, University of Cergy-Pontoise
}

\author{
AURÉLIEN SAÏDI \\ EconomiX, University of Paris Nanterre
}

The 2018 Sveriges Riksbank Prize in Economic Sciences in Memory of Alfred Nobel was awarded for "addressing some of our time's most basic and pressing questions about how we create long-term sustained and sustainable economic growth". It was shared by Yale's William Nordhaus, for portraying negative externalities due to greenhouse gas emissions in growth models (Kelleher 2019), and New York University's Paul Romer, "for integrating technological innovations into long-run macroeconomic analysis". The press release concludes that their contributions are "methodological ... [The] Laureates do not deliver conclusive answers" (The Royal Swedish Academy of Sciences 2018). Yet, the methods here acknowledged are very different in kind. Nordhaus is praised for his development of a quantitative "integrated assessment model" of how climate and economic growth affect each other, a model largely used to run simulations. Romer, by contrast, was crowned for his 10-year effort to develop a theory of endogenized growth, which culminated in the 1990 paper "Endogenous Technological Change".

According to the scientific background document written by the Committee for the Prize, "Romer's work was motivated by the data on macroeconomic aggregates and a more comprehensive cross-country data set which had just become available (Summers and Heston, 1984)" (The Committee for the Prize in Economic Sciences in Memory of Alfred Nobel 2018, 10). This statement is historically ambiguous, since such data did not exist when, as a graduate student, Romer decided to engage in a reconsideration of the source of growth. It also overshadows the primarily mathematical nature of Romer's quest and achievement, one that this paper strives to capture. His work stands as a reminder that non-empirical 
endeavors in economics are grounded in and fueled by economic reality, one that Romer sought to transform during his career. After unlocking the mathematics of growth, he went on to found an educational technology company, Aplia. It offered online homework products for college students. After selling it in 2007, he became an advocate of charter cities. Looking for institutional arrangements (rule of law) fostering growth, he suggested that the governance of developing economic regions should be outsourced to a more stable foreign nation. ${ }^{1}$ A controversial stint as chief economist of the World Bank followed, before he resumed his inquiry into how urban management can "improve the health, safety, and mobility of their citizens" and "help traditionally disenfranchised populations share in the benefits of rapid urbanization" (Romer 2019). This involved attending the Burning Man festival to understand its urban planning model (Badger 2019).

Romer is not just unusual in his career path, straddling intellectual, policy and advocacy endeavors, and in his public persona; he is also the only economist whose work was the subject of a thorough historical account years before it was recognized by a Nobel Prize. David Warsh (2006) has provided a thorough account of the bustling intellectual and institutional milieu throughout the 1980s in which Romer articulated the mathematical representation of the role of knowledge in the growth process. Drawing on the interviews, materials, and narratives assembled by Warsh, we thus begin by reconstructing the process whereby Romer came to write two path-breaking articles (1986b, 1990), each cited more than 27,000 times, ${ }^{2}$ which contributed to the launching of a large reinvestigation of the endogenous causes for growth in developing and developed countries. Because we interpret these papers as path-breaking contributions to mathematical theory, we then relate Romer's perception of his own work to his recent controversial statements on the uses of mathematics in theories of economic growth and in macroeconomics (Romer 2015a, 2016). Romer holds a unique view about how mathematics should be used in economic theorizing, and we situate his disagreement with other economists, in particular Robert Lucas, with respect to their beliefs about the correct degree of correspondence between real-world objects, economic concepts, and their mathematical representations.

\footnotetext{
${ }^{1}$ See Romer's TED talk (2009).

${ }^{2}$ According to Google Scholar citation data, consulted on October 15, 2019.
} 


\section{Providing a Richer And More SAtisfying Positive Theory of GROWTH}

A salient feature of Warsh's account of Romer's early student years is how unfashionable working on growth had become at the turn of the 1980s. Even Robert Solow had declared the field asleep. ${ }^{3}$ At the time Romer took his first economics classes at MIT (1977-1979), Solow was telling students that "anyone working inside economic theory these days knows in his or her bones that growth theory is not a promising pond for an enterprising theorist to fish in", also adding, "I think growth theory is at least temporarily played out" (quoted in Warsh 2006, 401).

Halfway through his graduate training, Romer decided to move back to Chicago. During a transition stint in Canada, he was introduced to John von Neumann's model of growth, which he found at odds with the rise of private research labs, universities, and patents he was observing. As he settled in Chicago, mathematical economist José Scheinkman had agreed to supervise his dissertation and allowed Robert Lucas to sit on his committee. As explained in the opening sentences of his dissertation, Romer's ambition was to "provide a richer and more satisfying positive theory of growth than is possible in the new standard formulation" (Romer 1983, 1). This was primarily intended as a mathematical endeavor, aimed at providing (and solving) a generic theoretical framework. He explained: "since the kind of model is applicable in a wide variety of economic problems, the mathematics per se may be of more fundamental interest than the specific application to growth" (Romer 1983, 1). Yet he also immediately acknowledged a tension between the mathematics and the objects they represent. The "mathematical appeal" of the optimizing models of Frank Ramsey (1928), Tjalling Koopmans (1965) and David Cass (1965) was "clear", he wrote: "the study of competitive equilibria can be reduced to the study of a familiar maximization problem". ${ }^{4}$ This, he reflected further, "must surely explain their general acceptance in the economics profession, for they are inconsistent with two basic observations" (Romer

\footnotetext{
${ }^{3}$ Solow wrote the reference model in which countries only escaped a stationary equilibrium (in which output per capita stalled) thanks to a mysterious exogenous "technological change" variable.

${ }^{4}$ The Cass-Koopmans model, based on Ramsey's 1928 pioneering work, was an attempt to refine Solow's 1957 exogenous growth model. This was done by replacing the Keynesian consumption function with optimizing behavior (a consumption/leisure tradeoff) in the investment/consumption plans of an infinitely lived household. It used mathematical programming (especially calculus of variations and optimal control), and was usually taught to students as an extension of Solow's model where consumption decisions are endogenized.
} 
1983, 2). First, technological change was clearly "the result of actions taken by economic agents" (Romer 1983, 2) rather than a spontaneous and occasional improvement in the production technology. ${ }^{5}$ Second, he drew on per capita growth rates collected by Simon Kuznets (1971) to highlight that growth in Western countries had been accelerating over the twentieth century. Romer wanted a mathematical model consistent with these observations.

The problem with the mechanisms that had been postulated to endogenize technical change and generate constant positive growth rates involved increasing returns to scale. Such a modeling strategy was difficult to handle mathematically, for it introduced non-convexities in the production set that ruled out standard optimization techniques. ${ }^{6}$ When Arrow first introduced learning-by-doing in growth in 1962, he was able to bypass the problem through simplifying hypotheses. Intrafirm increasing returns to scale also created an economic puzzle, one that was wellknown since Adam Smith. They fostered concentration, and thus perfect competition could not be preserved-the more firms produce, the lower the unit cost, and thus the higher the profit for constant input and output prices. Conversations with Sherwin Rosen led Romer to read Allyn Young's (1928) literary exposition of "economic growth driven by increasing returns resulting from specialization” (Romer 1983, 7). Without having read Alfred Marshall's Principles of Economics (1890), he modeled spillover effects internal to a sector but external to the firm, thereby avoiding the trend toward firm concentration and preserving a price-taking perfect competition setting. ${ }^{7}$ That was the only way "to deal with the technical problem, to make sure the math came out right", he later reflected (quoted in Warsh 2006, 567). While the resulting decentralized equilibrium could be proved to exist, it was necessarily suboptimal since firms do not take into account the positive social externalities they impose on each other. This created space for government intervention

\footnotetext{
${ }^{5}$ Romer's approach diverged from the one Finn Kydland and Edward Prescott (e.g. 1982) were developing around that time, one relying on stochastic exogenous technological shocks.

${ }^{6}$ From a technical viewpoint, maximizing over a convex set ensures the existence and uniqueness of an optimal solution. Relaxing this assumption may violate this property. ${ }^{7}$ Sectoral spillovers (in the form of knowledge production) are considered by firms as given when searching for the firms' optimal production decision, and are compatible with constant returns to scale (and so private decreasing returns to knowledge) at the firm level. At the aggregate or social level however they induce increasing returns to scale since spillovers increase with production.
} 
aimed at forcing agents to internalize the external effects and to invest more intensively in the production of knowledge.

The spillover model Romer had conceived in his dissertation was soon highlighted by Robert Lucas. Invited to give the Marshall lectures in Cambridge in 1985, Lucas chose to walk the audience through a menagerie of models which had something to say about countries' differentiated growth rates. By this time, important new data had become available. Carrying over a project launched by Irving Kravis at the University of Pennsylvania in the 1960s, Alan Heston and Robert Summers collected GDP, consumer expenditures, capital formation, public expenditures and other data for more than 100 countries (Summers and Heston 1988). Country data was made comparable through the development of purchasingpower parity indexes. What came to be known as the Penn World Tables was published in 1982 and updated regularly afterwards. These data documented at great length the lack of convergence between countries. ${ }^{8} \mathrm{Lu}-$ cas (1988a) considered both capital accumulation and what he called, in the Chicago tradition of Schultz (1963) and Gary Becker (1964), human capital accumulation, through either schooling or learning-by-doing. He outlined a two-sector growth model where human capital was used to produce (and accumulate) human capital according to a non-decreasing returns technology. He replaced Romer's sectoral spillovers with the idea of a human capital externality. Like his former student, he obtained a suboptimal social equilibrium. But unlike Romer, he did not discuss possible public intervention.

By the time his model of endogenous growth with spillovers went to press (Romer 1986b), Romer had however started to work with models of monopolistic competition. In doing so, he was connecting with longstanding debates which had been reignited with Arrow's 1962 article. Harold Demsetz (1969) challenged Arrow's ambition to draw relevant conclusions about the optimal allocation of resources for invention and associated economic policy prescriptions from a pure theoretical framework of perfect competition. Rather, he pushed for a monopolistic framework, one later developed by Partha Dasgupta and Joseph Stiglitz (1980). Their

\footnotetext{
${ }^{8}$ In Solow's (1957) model, countries with similar characteristics (relating to technology and demographic growth) but lower states of 'development' (more precisely lower capital per capita accumulation) benefit from a higher growth rate which allows them to catch up with the most advanced countries. This phenomenon known as 'absolute convergence' is clearly rejected on the ground of empirical plausibility. Subsequent models, and especially models of endogenous growth, aimed at resolving the discrepancy between theory and data, and at explaining persistent growth gaps across countries (for a more exhaustive treatment of absolute and conditional convergences, see Romer 1994).
} 
article articulated an endogenized market structure and introduced R\&D expenditure. ${ }^{9}$ It was only after he defended his thesis in 1983 and moved to Rochester that Romer took up these themes. There, he pursued extensive discussions with fellow assistant professor Robert Barro and general equilibrium theorist Lionel McKenzie. He read the work of Avinash Dixit, Joseph Stiglitz and Paul Krugman on specialization, and performed econometric work to explain the hot topic of productivity slowdown in the United States. Finally, he reflected on which characteristics of knowledge would make agents produce and spur growth. In 1988, he presented a paper entitled "Micro-foundations for Aggregate Technological Change", providing a rationale for agents to pursue knowledge. This was an early version of the paper to which he later gave the simpler title "Endogenous Technical Change" (1990).

It was a paper on the pricing of ski-lifts, written with Barro (Barro and Romer 1987), that led Romer to reflect on Paul Samuelson's (1954) work on public versus private goods and James Buchanan's (1968) intermediate notion of club goods. In the process, Romer refined what he believed were the crucial characteristics of knowledge: they were not indivisibility, as Arrow had previously emphasized, but a combination of non-rivalry and partial excludability. The latter, Romer claimed in his (1990) paper, explains why economic agents might choose to invest in the production of new ideas. He proposed a model in which profit-maximizing entrepreneurs hunt for new ideas because of the gains temporary patents would provide them. Romer thus made producing knowledge a profit generating activity in a monopolistic competition framework. Because those ideas are non-rivals, that is, can be used by many agents at the same time without being depleted, the resulting knowledge spillovers create sustainable growth.

\section{Solving Mathematical RidDles OR MATChING DATA?}

Romer's contribution was thus primarily a mathematical tour de force, transposing in a neoclassical dynamic general equilibrium framework both Young's ideas about the specialization origins of growth and those of Marshall on increasing returns. He detailed his mathematical treatment of non-convexities and associated non-conventional solutions (such as chattering equilibria or equilibria with jumps) in an article published in Econometrica (Romer 1986a). Romer's original ambition and mathemati-

\footnotetext{
${ }^{9}$ These are just two examples of the many reactions to Arrow's (1962) paper. See Backhouse (1999) for a thorough survey.
} 
cal accomplishment gave rise to a new growth economics and spurred thousands of research articles. They are, however, missing both from most textbooks and from the Nobel committee's review, which did not mention the above article. What was retained was the general idea of knowledge accumulation, and the conditions for sustainable growth. The preservation of a general equilibrium framework was also important for Romer:

Remember my thesis, and how it was articulated, I had these general equilibrium ambitions, I was hoping people would pay attention to that, but they didn't. On the other hand it was a little too abstract for the Solow types, the MIT types, who said, just give me the equation, don't worry about the logic and assumptions. I don't think either of those paths ultimately would have led to the clarification of what do we mean by an externality, as opposed to what do we mean by a nonrival good. That's where the rigor and logic of General Equilibrium math really paid off. (quoted in Warsh 2006, 595)

At the same time, Romer insisted that mathematical modeling needed to be checked, ex ante and ex post, by empirical evidence. "I often draw a picture for my students of different levels", he later explained. "The highest degree of abstraction is at the top, the closest contact to the world of our senses at the bottom. The theorist follows a trajectory within these bounds. You zoom up, spend some time, and zoom back down again" (quoted in Warsh 2006, 568). Such a process is echoed in the structure of his papers. From Kuznets' data which featured in his dissertation, he gradually came to introduce historical data on growth gathered by Angus Madison (Romer 1986b) and Summers and Heston (Romer 1987a), as well as histories of innovation and technological progress by Stanford economists Nathan Rosenberg, Moses Abramovitz and Paul David. Invited to present at the macroeconomics conference of the NBER in 1987 (Romer 1987b), he wrote his first empirical defense of long-term economic growth driven by increasing returns and spillovers effects.

Nearly a decade later, an American Economic Association (AEA) session on "New Growth Theory and Economic History: Match or Mismatch" offered him the opportunity to articulate more strongly his vision of the interplay of theory and historical evidence (Romer 1996). He faulted those economists, who, like Gregory Mankiw (1995), retained a price-taking competitive framework (especially at the time it was becoming common to use imperfect competition in DSGE models). When they assume that "technology is the same in all countries and conclude that exogenous 
differences in saving and education cause all of the observed differences in levels of income and rates of growth" (Romer 1996, 202), they disregard the most elementary facts, Romer bemoaned. But he also rejected the proponents of "history without theory" who believe that "these equations are so simplistic, and the world is so complicated" (ibid.). He went on to offer a defense of formal methods, some geared toward the explanation of observed patterns: "What theories do is take all the available complicated information about the world and organize it into this kind of hierarchical structure ... What growth theory must do is provide a good, simple split of the opportunities available in the physical world" (Romer 1996, 203).

Romer's contribution to the 1996 session foreshadowed the attack he would launch on growth theory and more largely macroeconomics at the AEA annual meeting, almost twenty years later. During a session on "Reflections on New Growth Theory", Romer bluntly accused Lucas, who had just presented on human capital and growth, of indulging in 'mathiness'. The word echoed entertainer Stephen Colbert's remark that some statements have an air of truth in spite of being grounded in no evidence, one he called 'truthiness'. Mathiness, Romer $(2015 \mathrm{a}, 89)$ wrote in the published version of his talk, "uses a mixture of words and symbols, but instead of making tight links, it leaves ample room for slippage between statements in natural versus formal language and between statements with theoretical as opposed to empirical content". What he targeted was Lucas' assumption that every present and future productive technology is already used at time zero and the observationally equivalent interpretation proposed. He faulted other economists with similarly 'dishonest' practices, which seemed to include a mix of unrealistic assumptions, shaky interpretations of mathematical symbols, and mistakes in manipulating those symbols (Warsh 2015). ${ }^{10}$

That most of them were associated with Minnesota and Chicago and used price-taking models reveals that what Romer was reeling against was their lack of endorsement of his monopolistic competition framework, which he argued prevented economists from moving toward the 'shared consensus' characteristic of a healthy science. ${ }^{11}$ Romer did not accuse Lucas of using questionable methods in order to reach specific policy prescriptions, but Lucas seems to have understood their exchange that way:

\footnotetext{
${ }^{10}$ Romer (2016) elaborated on what he considered mathiness in a follow-up paper targeting macroeconomics, one again largely aimed at Lucas.

${ }^{11}$ Duarte (2015) argues that it was precisely the consensus around stylized facts on the business cycle which needed to be explained that created a trading zone where macroeconomists could negotiate their theoretical disagreements in the 1990s.
} 
"If anyone sees anything like politics in Romer's JPE [1990 Journal of Political Economy] article, let me know" he responded (quoted in Warsh 2015). "What I'm saying does not line up with familiar critiques about political ideology in economics", Romer (2015b) later clarified in a blog post. What Romer indicted was academic politics and methodological dogma: "[the people I criticize] are fighting to preserve a sense of academic group identity grounded in a common defense of this dogmatic position" he outlined in that same blog post.

\section{Why (AND How) TheOrists MAKe Assumptions: CARVING a SYSTEM}

\section{AT THE JOINTS?}

The endogenous growth literature honored by the Nobel committee was underpinned by a shared methodology. Models were built in response to patterns observed in the data that were inconsistent with the main conclusions of the standard model, with the mathematics being used to bridge the gap between facts and theories. Like Romer (1986b), Lucas opened his seminal "On the Mechanics of Economic Development" (1988a) with a survey of The World Bank's World Development Report (1983) and of Summers and Heston's data (1988), documenting sharp divergences between per capita income across countries. He then explained that he was looking for a theory of economic development "to provide some kind of framework for organizing facts like these, for judging which represent opportunities and which necessities" (Lucas 1988a, 5). Romer acknowledged that, in those years, a consensus existed both on which observed patterns were problematic and on how to approach them: "both Robert Lucas (1988[a]) and I (Romer, 1986[b]) cited the failure of crosscountry convergence to motivate models of growth that drop the two central assumptions of the neoclassical model: that technological change is exogenous and that the same technological opportunities are available in all countries of the world" $(1994,4) .^{12}$

However, Romer's attack on mathiness shows that he and Lucas disagreed sharply on how mathematics and the real world should interact in the process of developing theoretical assumptions. When he attacked Lucas for relying on an unrealistic assumption on the degree of technological knowledge possessed by the model's agents, Lucas responded: "Every theory contains assumption $[s i c]$ that are not quite true. That's what

\footnotetext{
${ }^{12}$ Hirschman (2016) documents how economists and other social scientists came to call these empirical regularities in search of theoretical, causal explanations "stylized facts". See also footnote 7 .
} 
makes it theory" (quoted in Warsh 2015). In his (1988a) article, Lucas elaborated what he means by "theory":

An explicit dynamic system, something that can be put on a computer and run. This is what I mean by the 'mechanics' of economic development - the construction of a mechanical artificial world, populated by the interacting robots that economics typically studies, that is capable of exhibiting behavior the gross features of which resemble those of the actual world that I have just described. (Lucas 1988a, 5)

Here, Lucas summarized what he has claimed in many other publications and speeches: that models are "artificial" worlds $(1980,696)$ and abstractions $(1990,664)$, but that they need to be good "imitations" of real facts (Lucas 1980, 697; 2011, 105) and of "some of the main features of the economic behavior we observe in the world economy" (Lucas 1988a, 39; see also Sergi 2017; Goutsmedt 2018; and Goutsmedt, Guizzo, and Sergi 2019). In a commencement address delivered at the University of Chicago the same year, he explained that the task of economists was to look for "better and more instructive analogies". Economists "are storytellers, operating much of the time in worlds of make believe", he explained, "We do not find that the realm of imagination and ideas is an alternative to, or retreat from, practical reality. On the contrary, it's the only way we have found to think seriously about reality" (Lucas 1988b).

Lucas' view on the relation between assumptions and reality has been interpreted as 'ambivalent'. Sergi (2017) points out that Lucas generally prioritized the internal consistency of theoretical assumptions, yet sometimes he wrote that there must be some 'analogy' between assumptions and reality if policy conclusions are to be drawn. In contrast, our hypothesis is that what matters for Lucas is not the analogy between assumptions and real behavior, but between model and real-world outcomes. In testimony before the Pontifical Academy of Sciences in 2011, Lucas (2011, 105-106) acknowledged that the homo oeconomicus model describes a way "actual people never are", but he considered that the resulting "situation", in which each agent is acting in a way that is individually rational yet collectively irrational, to be "common in actual society". ${ }^{13}$ In a review of Elhanan Helpman and Paul Krugman's Trade Policy and Market Structure (1989), he further justified the unrealism of assumptions as providing a tractable and unique general model: "One is able to see which

\footnotetext{
${ }^{13}$ Mancur Olson's paradox of collective action is perhaps the most striking example (Olson 1965).
} 
assumptions are essential to which results with a clarity that is just not possible through the study of special cases as they appear in journal articles" (Lucas 1990, 664). If realism had to be traded for tractability, then so be it. Lucas viewed the kind of theoretical model that he, or Helpman and Krugman, produced as a first stage in a larger process whereby the model is subsequently tested against out-of-sample data (Lucas 1988a, 5). The model was then used to fashion more "specific models that seem to capture situations in particular industries, and thus they permit the exercise of judgment and the use of evidence to help determine which theoretically possible effects are small and which are critical" (Lucas 1990, 665; emphasis added).

The general patterns of growth researched in the 1980s saw Romer's and Lucas' research questions coming together, and formed the benchmark against which their models of growth needed to be evaluated. But Lucas was willing to adopt assumptions which did not reflect economic agents' observed behavior if they allowed him to devise a 'mechanism' that replicated a wider range of phenomena, possibly isolating a common effect. He would come up with a mathematical expression, then some stories about the underlying economic behavior. In contrast, Romer drew on the history of technological innovation to develop conceptual distinctions between "ideas" and "things", and behavioral assumptions on what drives entrepreneurs. This would determine the type of framework and mathematical solution concept he adopted.

Though Romer's early contributions did not feature any epistemological statements, he articulated such a framework in his (1996) contribution to an AEA session on theory and economic history. Drawing on Richard Dawkins's "hierarchical reductionism", Romer $(1996,203)$ explained that the task of the scientist is to describe real-world phenomena by distinguishing, classifying and combining their main structural elements. For instance, he contended that distinguishing between "ideas" and "things" was a better classification of growth input than public versus private goods. Romer explained that the original phenomena can thus be progressively reduced to a conjunction of interacting atomic elements:

Explanation operates on many levels that must be consistent with each other. What theories do is take all the available complicated information about the world and organize it into this kind of hierarchical structure. In building this structure, good theory indicates how to carve a system at the joints. At each level, theory breaks a system 
down into a simple collection of subsystems that interact in a meaningful way. (1996, 203; emphasis added)

In his paper addressing mathiness, Romer further insisted that each theoretical element remained empirically interpretable, i.e. analogous to an identifiable object in the real-world, as they become encapsulated in mathematical symbols. He praised how Solow's mathematical theory of growth "mapped the word 'capital' onto a variable in his mathematical equations, and onto both data from national income accounts and objects like machines or structures that someone could observe directly", and how Gary Becker's theory of wage likewise "gave the words 'human capital' the same precision and established the same two types of tight connection-between words and math and between theory and evidence" (2015a, 89). He concluded that maintaining a "tight connection" between the data to be explained, the words used to denote abstract concepts such as "technology", and the mathematical symbols and equations used to represent their relationships with one another was key. He faulted economists, such as Lucas, for using words and mathematical assumptions which have no meaning and no precise counterpart in reality. He rejected hypotheses based on "immaterial entities or processes, such as disembodied spirits" (to quote philosopher of science Mario Bunge 1983, 224). This is the case not only for words like 'technology', but also for 'technological shocks', which he believes Kydland and Prescott "might as well have called ... gremlins or unicorns" (Paul Romer, personal correspondence, October 2015).

The fundamental divide between Romer and Lucas, therefore, appears to be the degree of correspondence they believe should exist between real-world entities and concepts expressed through words and mathematical entities. What remains unclear for Romer, is how to define the acceptable degree of convergence or divergence. He questions the way macroeconomists use the word 'technology' and the way technology is represented, but he does not question other abstractions such as capital-labor substitution, firms (in the neoclassical sense of the term, i.e. without any social structure) or production functions. He even accuses economists who openly challenged the existence of the kind of production functions Solow used, such as Joan Robinson, of engaging in mathiness (Romer 2015a, 89). ${ }^{14}$ However, as both the two Cambridges controversy and Romer's own endogenous growth theory show, all important economic

\footnotetext{
${ }^{14}$ See Backhouse (2014) for an account of the two Cambridges controversy.
} 
abstractions and associated mathematical representations are meant to be challenged by more specific and therefore empirically relevant ones. Lucas' endorsement of artificial worlds dodges the issue of the proper degree of connection to the real world altogether, yet it does not seem to shield his models from criticism.

The question of the convergence between theoretical categories and real-world objects has, in fact, been a major concern in the epistemology and philosophy of science, as exemplified by the debates surrounding Romer's use of a quote by Plato. His idea that "good theory indicates how to carve a system at the joints" (Romer 1996, 203) was, in fact, a rendition of a famous line from the Phaedrus (265e): "The second principle is that of division into species according to the natural formation, where the joint is, not breaking any part as a bad carver might" (translation by Benjamin Jowett). The resulting phrase, "carving nature at its joints", had generated centuries of debates about whether the world possesses "joints" upon which "natural kinds" of entities can be distinguished. In association with these debates is the question of whether scientific knowledge depends upon the discovery of new categories or the invention of them (Slater and Borghini 2011). In the end, it seems that Romer and Lucas have been caught in another ripple of the millennium-old science debate of whether to become a butcher or a toymaker.

\section{REFERENCES}

Arrow, Kenneth. 1962. "Economic Welfare and the Allocation of Resources for Invention." In The Rate and Direction of Inventive Activity: Economic and Social Factors, 609-625. Princeton: Princeton University Press.

Backhouse, Roger E. 1999. "Modelling Invention: The Use of Models in the Neoclassical Literature on R\&D." In From Classical Economics to the Theory of the Firm: Essays in Honour of D. P. O'Brien, edited by Roger E. Backhouse, and John Creedy, 1-13. Cheltenham: Edward Elgar.

Backhouse, Roger E. 2014. "MIT and the Other Cambridge." History of Political Economy 46 (supp_1): 252-271.

Badger, Emily. 2019. “A Nobel-Winning Economist Goes to Burning Man.” The New York Times, September 5, 2019. https://www.nytimes.com/2019/09/05/upshot/paulromer-burning-man-nobel-economist.html.

Barro, Robert J., and Paul M. Romer. 1987. "Ski-Lift Pricing, with Applications to Labor and Other Markets." The American Economic Review 77 (5): 875-890.

Becker, Gary S. 1964. Human Capital: A Theoretical and Empirical Analysis, with Special Reference to Education. New York, NY: National Bureau of Economic Research.

Buchanan, James M. 1968. The Demand and Supply of Public Goods. Chicago, Ill: Rand McNally and Company. 
Bunge, Mario. 1983. Treatise on Basic Philosophy. Volume 6. Epistemology and Methodology II: Understanding the World. Dordrecht: Springer Science+Business Media Dordrecht.

Cass, David. 1965. "Optimum Growth in an Aggregative Model of Capital Accumulation." The Review of Economic Studies 32 (3): 233-240.

Dasgupta, Partha, and Joseph Stiglitz. 1980. "Industrial Structure and the Nature of Innovative Activity.” The Economic Journal 90 (358): 266-293.

Demsetz, Harold. 1969. "Information and Efficiency: Another Viewpoint." The Journal of Law and Economics 12 (1): 1-22.

Duarte, Pedro G. 2015. "From Real Business Cycle and New Keynesian to DSGE Macroeconomics: Facts and Models in the Emergence of a Consensus." Department of Economics FEA/USP Working Paper No. 2015-05.

Goutsmedt, Aurélien. 2018. "Thomas Sargent Face à Robert Lucas: Une Autre Ambition pour la Nouvelle Economie Classique.” CEconomia 8 (2): 211-241.

Goutsmedt, Aurélien, Danielle Guizzo, and Francesco Sergi. 2019. "An Agenda without a Plan. Robert E. Lucas's Trajectory through the Public Debate." CEconomia 9 (2): 289314.

Hirschman, Dan. 2016. "Stylized Facts in the Social Sciences." Sociological Science 3: 604626.

Kelleher, Paul J. 2019. "Reflections on the 2018 Nobel Memorial Prize Awarded to William Nordhaus." Erasmus Journal for Philosophy of Economics 12 (1): 93-107.

Koopmans, Tjalling. 1965. "On the Concept of Optimal Economic Growth.” In The Econometric Approach to Development Planning, 225-287. Chicago, Ill: Rand McNally and Company.

Kuznets, Simon. 1971. "Notes on the Pattern of U.S. Economic Growth." In The Reinterpretation of American Economic History, edited by Robert W. Fogel, and Stanley L. Engerman, 17-24. New York, NY: Harper \& Row.

Kydland, Finn E., and Edward C. Prescott. 1982. "Time to Build and Aggregate Fluctuations." Econometrica 50 (6): 1345-1370.

Lucas, Jr., Robert E. 1980. "Methods and Problems in Business Cycle Theory." Journal of Money, Credit and Banking 12 (4): 696-715.

Lucas, Jr., Robert E. 1988a. “On the Mechanics of Economic Development.” Journal of Monetary Economics 22 (1): 3-42.

Lucas, Jr., Robert E. 1988b. “What Economists Do.” Lecture at The University of Chicago. Accessed October 15, 2019. https://economianostra.wordpress.com/2014/02/25/ what-economists-do-by-robert-lucas/.

Lucas, Jr., Robert E. 1990. "Book Review of Trade Policy and Market Structure by Elhanan Helpman, and Paul R. Krugman.” Journal of Political Economy 98 (3): 664-667.

Lucas, Jr., Robert E. 2011. "Ethics, Economic Policy and the Understanding of Economic Development." In Social and Ethical Aspects of Economics: A colloquium in the Vatican, edited by the Pontifical Council for Justice and Peace, 105-139. Vatican City: Vatican Council.

Mankiw, N. Gregory. 1995. "The Growth of Nations." Brookings Papers on Economic Activity 1: 275-326.

Marshall, Alfred. 1890. Principles of Economics. Great Minds Series. London: Macmillan.

Olson, Mancur. 1965. The Logic of Collective Action: Public Goods and the Theory of Groups. Cambridge, MA: Harvard University Press. 
Ramsey, Frank P. 1928. “A Mathematical Theory of Saving.” The Economic Journal 38 (152): 543-559.

Romer, Paul M. 1983. "Dynamic Competitive Equilibria with Externalities, Increasing Returns and Unbounded Growth." PhD dissertation, University of Chicago.

Romer, Paul M. 1986a. "Cake Eating, Chattering, and Jumps: Existence Results for Variational Problems." Econometrica 54 (4): 897-908.

Romer, Paul M. 1986b. "Increasing Returns and Long-Run Growth." The Journal of Political Economy 94 (5): 1002-1037.

Romer, Paul M. 1987a. “Growth Based on Increasing Returns Due to Specialization.” The American Economic Review 77 (2): 56-62.

Romer, Paul M. 1987b. “Crazy Explanations for the Productivity Slowdown." In NBER Macroeconomics Annual 1987: Volume 2, edited by Stanley Fischer, 163-201. Cambridge, MA: The MIT Press.

Romer, Paul M. 1990. "Endogenous Technological Change.” Journal of Political Economy 98 (5): S71-S102.

Romer, Paul M. 1994. “The Origins of Endogenous Growth.” Journal of Economic Perspectives 8 (1): 3-22.

Romer, Paul M. 1996. "Why, Indeed, in America? Theory, History, and the Origins of Modern Economic Growth.” The American Economic Review 86 (2): 202-206.

Romer, Paul M. 2009. "Why the World Needs Charter Cities." TED. Accessed October 15, 2019. https://www.ted.com/talks/paul_romer_why_the_world_needs_charter_cities?language $=\mathrm{en}$.

Romer, Paul M. 2015a. "Mathiness in the Theory of Economic Growth." American Economic Review: Papers \& Proceedings 105 (5): 89-93.

Romer, Paul M. 2015b. “Mathiness and Academic Integrity.” Personal Blog of Paul Romer. May 27, 2015. https://paulromer.net/mathiness-and-academic-identity/.

Romer, Paul M. 2016. “The trouble with Macroeconomics.” Working Paper.

Romer, Paul M. 2019. “About.” Personal Website of Paul Romer. Accessed October 15, 2019. https://paulromer.net/about/.

Samuelson, Paul A. 1954. "The Pure Theory of Public Expenditure." The Review of Economics and Statistics 36 (4): 387-389.

Schultz, Theodore W. 1963. The Economic Value of Education. New York, NY: Columbia University Press.

Sergi, Francesco. 2017. "Models as Laboratories. Robert E. Lucas on Expertise." Mimeo. Communication at the Annual 2017 Meeting of the European Society for the History of Economic Thought.

Slater, Matthew H., and Andrea Borghini. 2011. "Introduction: Lessons from the Scientific Butchery." In Carving Nature at Its Joints: Natural Kinds in Metaphysics and Science, edited by Joseph Keim Campbell, Michael O'Rourke, and Matthew H. Slater, 1-31. Cambridge, MA: The MIT Press.

Solow, Robert M. 1957. "Technical Change and the Aggregate Production Function." The Review of Economics and Statistics 39 (3): 312-320.

Summers, Robert, and Alan Heston. 1988. "A New Set of International Comparisons of Real Product and Price Levels Estimates for 130 Countries, 1950-1985." The Review of Income and Wealth 34 (1): 1-25.

The Committee for the Prize in Economic Sciences in Memory of Alfred Nobel. 2018. "Scientific Background on the Sveriges Riksbank Prize in Economic Sciences in 
Memory of Alfred Nobel 2018: Economic Growth, Technological Change, and Climate Change." Nobelprize.org. Accessed October 15, 2019. https://www.nobelprize.org/uploads/2018/10/advanced-economicsciencesprize2018.pdf.

The Royal Swedish Academy of Sciences. 2018. "Press release: The Prize in Economic Sciences 2018." Nobelprize.org. Accessed October 15, 2019. https://www.nobelprize.org/prizes/economic-sciences/2018/press-release/.

The World Bank. 1983. World Development Report 1983. New York, NY: Oxford University Press.

Young, Allyn A. 1928. "Increasing Returns and Economic Progress." The Economic Journal 38 (152): 527-542.

Warsh, David. 2006. Knowledge and the Wealth of Nations: A Story of Economic Discovery. New York, NY: W. W. Norton \& Company Inc.

Warsh, David. 2015. "Economist, Interrupted.” Economic Principals. January 25, 2015. http://www.economicprincipals.com/issues/2015.01.25/1685.html.

Beatrice Cherrier is a researcher at CNRS and CY Cergy Paris University. She researches the history of the 'applied turn' in economics since the 1970s, with some focus on the history of female applied economists, institutional markers of disciplinary structures such as the JEL codes or the John Bates Clark medal, and the history of applied fields including macroeconomics, public, and urban economics.

Contact e-mail: <beatrice.cherrier@gmail.com>

Aurélien Saïdi is an associate professor at the Department of Economics at Université Paris Nanterre. His research focuses especially on the macroeconomics of self-fulfilling prophecies and the history of economic thought in the $20^{\text {th }}$ century. He has coauthored several papers with Beatrice Cherrier.

Contact e-mail: <aurelien.saidi@parisnanterre.fr> 